\title{
Caracterización clínica-epidemiológica de pacientes con coinfección criptococosis - VIH del Hospital José Rodríguez 2015 $-2016$
}

\section{Clinical-epidemiological characterization of patients with cryptococcosis coinfection - VIH of José Rodríguez hospital 2015 - 2016}

\author{
Sara Elizabeth Bravo Salinas ${ }^{1 *}$ y Alex Alberto Castillo Zhizhpón ${ }^{2}$ \\ ${ }^{1}$ Universidad Católica de Cuenca \\ 2 Instituto Ecuatoriano de Seguridad Social \\ *sara.bravo@ucacue.edu.ec
}

DOI: https://doi.org/10.26871/killkana_salud.v3i3.522

\begin{abstract}
Resumen
Contexto: El VIH continúa siendo uno de los mayores problemas para la salud pública mundial, se ha cobrado más de 35 millones de vida, en 2016, un millón de personas fallecieron en el mundo por causas relacionadas con este virus. La criptococosis una micosis sistémica producida por el Cryptococcus neoformans se presenta en pacientes con VIH/SIDA con inmunosupresión avanzada causando la muerte de las dos terceras partes de estos pacientes. Objetivo: Caracterizar clínica y epidemiológicamente los pacientes que presentan coinfección criptococosis y VIH del Hospital José Daniel Rodríguez Maridueña en el período 2015 - 2016. Procedimientos: Estudio descriptivo, transversal, retrospectivo basado en el análisis de las historias clínicas de los pacientes con diagnóstico de ingreso de criptococosis y VIH, del Hospital Dr. José Rodríguez ingresados entre los años 2015 y 2016. Analizado mediante Razón de prevalencias y OR e ICIC $95 \%$ calculado mediante distribución binomial y la interacción entre las variables se analizó mediante regresión logística. Resultados: La tasa de coinfección fue 46,7\% ( $\mathrm{IC}_{95} \%$ 39,48-53,84), el análisis conjunto de las variables demostró que estas personas son menores de 32 años (ORajustada 2,24; IC I $_{95}$ 1,09-4,57), casado o en unión libre (ORajustada 2,56; IC $_{95} \%$ 1,26-5,26), que supera la primaria (ORajustada 3,36; $\mathrm{IC}_{95} \%$ 1,52-7,42), consumidor de drogas (ORajustada 2,63; IC $95 \%$ 1,28-5,26), con una carga viral mayor a 100000 copias de RNA/mL (ORajustada 3,74; $\mathrm{IC}_{95} \%$ 1,80-7,80). Conclusiones: El perfil de riesgo del paciente con coinfección criptococosis y VIH fue ser adulto joven, casado o en unión libre, con un nivel de instrucción superior a la primaria, que consume drogas, con una carga viral mayor a 100000 copias de RNA/ml.
\end{abstract}

Palabras clave: carga viral, criptococosis, drogas, VIH, SIDA.

\begin{abstract}
Context: HIV remains one of the world's greatest public health challenges, claiming more than 35 million lives. Cryptococcosis is a systemic mycosis produced by Cryptococcus neoformans. It occurs in HIV/AIDS patients with advanced immunosuppression, causing the death of two thirds of these patients. Objetive: To characterize the patients that present coinfection cryptococcosis and HIV of the Hospital José Daniel Rodríguez Maridueña in the period 2015 - 2016. Methodology: A descriptive, cross-sectional, retrospective study based on the analysis of clinical histories of patients diagnosed with cryptococcosis and HIV admission at Hospital Dr. José Rodríguez admitted between 2015 and 2016. Analyzed by prevalence ratio and $O R$ and $I C_{95 \%}$ calculated by binomial distribution and the interaction between variables was analyzed by logistic regression. Results: The coinfection rate was $46.7 \%\left(C I_{95 \%} 39.48-53.84\right)$, the pooled analysis of the variables showed that these people were younger than 32 years (OR adjusted 2.24; $C I_{95 \%}$ 1.09-4.57), married or in union (OR adjusted 2.56); IC $95 \%$ 1.26-5.26), above primary (OR adjusted 3.36, IC $95 \%$ 1.52-7.42), drug user (OR adjusted 2.63, IC $95 \%$ 1.28-5.26), with a viral load greater than 100000 (OR adjusted 3.74, IC $95 \%$ 1.80-7.80). Conclusions: The risk profile of a patient with cryptococcosis coinfection and HIV is to be less than 32 years old, married or in a free union, with a higher level of education than primary school, who uses drugs, with a viral load greater than 100,000 .
\end{abstract}

Keywords: viral load, cryptococcosis, drugs, HIV, AIDS. 


\section{Introducción}

Hace más de dos décadas se describieron los primeros casos de la infección por el Virus de la Inmunodeficiencia Humana (VIH) y el desarrollo del Síndrome de Inmunodeficiencia Adquirida (SIDA). Las primeras manifestaciones que fueron consideradas como marcadoras de SIDA eran la aparición de infecciones oportunistas producidas por microorganismos, por lo general, considerados no patógenos para el humano. Dentro de este grupo de infecciones oportunistas se encontraban los hongos, principalmente, Pneumocystis jirovecii (antes P. carinii), Candida albicans, Cryptococcus neoformans e Histoplasma. ${ }^{1-3}$

En la actualidad, a pesar de la introducción de la terapia antirretroviral altamente efectiva (TARGA) y al desarrollo de nuevos procedimientos y técnicas diagnósticas, continúan las altas tasas de morbilidad y mortalidad en los países con recursos limitados, debido al acceso restringido que tienen los pacientes a estos avances. Sin embargo, en el Ecuador dicho tratamiento no tiene costo ya que el Ministerio de Salud Pública es la institución del Estado que provee los gastos del tratamiento en todos los casos de VIH. ${ }^{4}$

A nivel mundial la mortalidad a causa del VIH se ha reducido de forma notable con la implementación del Tratamiento Antiretroviral (TARV) con una cifra estimada de 1,1 millones (intervalo de 940000 a 1,3 millones) en el año 2015, lo cual representa un $43 \%$ menos que en el año 2003, cuando se fijaron por vez primera las metas terapéuticas. ${ }^{2}$

En el Ecuador para el año 2016 se registraron que 33.000 personas viven con VIH, de estas 30.000 (92\%) conocen su estado, la tasa de prevalencia del VIH en adultos de 15 a 49 años es de $0.3(0.2-0.4), 1.900(1.100-2.800)$ adultos y niños recientemente infectados con VIH, la incidencia de VIH por 1.000 habitantes entre 15-49 años es de 0,22 $(0,13-0,32)$, las muertes de adultos y niños debido al SIDA se estima $<1.000(<500-1.100)$, hay 10000 (7.100-14.000) huérfanos por SIDA de 0 a 17 años, la cobertura de adultos y niños que reciben TARV es del $52 \%$ (38\%-66\%), la cobertura de mujeres embarazadas que reciben ARV es $>95 \%$, el diagnóstico infantil temprano, $89 \%$.

\section{Metodología}

El presente estudio es descriptivo transversal, retrospectivo mediante al análisis de las historias clínicas de aquellos pacientes VIH-positivos hospitalizados entre lo años 2015 y 2016, diagnosticados presuntivamente de criptococosis en el Hospital Dr. José Daniel Rodríguez Maridueña ubicado en la ciudad de Guayaquil, provincia del Guayas (Ecuador).

\subsection{Población de estudio}

La población de estudio fueron los habitantes de las diferentes provincias del Ecuador mayores de 18 años con diagnóstico de VIH, que fueron por demanda espontánea al área de consulta externa o emergencia y terminaron siendo ingresados con diagnóstico presuntivo de criptococosis entre lo años 2015 y 2016.

De esta manera se pudo analizar un total de 195 historias clínicas, de los cuales 91 pacientes tuvieron diagnóstico definitivo de coinfección criptococosis-VIH, y en 104 pacientes se descartó dicho diagnóstico mediante la negativización para criptococosis en los exámenes complementarios, los cuales revelaron otras patologías.

Los criterios de inclusión para el estudio son:

1) Pacientes con diagnóstico previo de VIH, y diagnóstico presuntivo de criptococosis al momento del ingreso hospitalario.

2) Disponibilidad de la historia clínica y disponibilidad de resultados de exámenes complementarios en las historias clínicas.

3) Egresados del Hospital Dr. José Daniel Rodríguez Maridueña entre los años 2015 y 2016 con diagnóstico definitivo de coinfección.

El presente estudio se desarrolló bajo la aprobación del campus Esther de la Universidad Rey Juan Carlos de España, previa autorización del Director Técnico y del Jefe de Docencia del Hospital Dr. José Rodríguez Maridueña. El análisis de los datos se realizó de febrero a marzo de 2018; mediante el programa SPSS y se procedió al control de calidad.

La recategorización de las variables fueron trabajadas en el programa estadístico SPSS V.20, mediante la opción recodificar (recode), ${ }^{6}$ condición fundamental para luego realizar el análisis estadístico, cuadro 1.

Tabla 1. Recodificación de variables a partir de base de datos "VIH"

\begin{tabular}{|c|c|c|}
\hline Variable original & Variable recodificada & Justificación \\
\hline $\begin{array}{l}\text { Edad } \\
\text { Desde } 18 \text { a } 99 \text { años }\end{array}$ & $\begin{array}{l}0=\text { Menor de } 32 \text { años } \\
1=\text { Igual o mayor de } 32 \text { años }\end{array}$ & $\begin{array}{l}\text { La edad se recategorizó en función de la } \\
\text { media obtenida de los pacientes con coinfec- } \\
\text { ción. }\end{array}$ \\
\hline $\begin{array}{l}\text { Estado civil } \\
\text { 1= Soltero } \\
\text { 2= Casado } \\
\text { 3=Viudo } \\
\text { 4=Divorciado } \\
\text { 5= Unión libre }\end{array}$ & $\begin{array}{l}0=\text { Casado o en unión libre } \\
1=\text { Otros }\end{array}$ & $\begin{array}{l}\text { Se clasificó en dos grupos tomando en con- } \\
\text { sideración el grupo mayoritario presente en } \\
\text { los pacientes con coinfección. }\end{array}$ \\
\hline
\end{tabular}


Tabla 1. Recodificación de variables a partir de base de datos "VIH"... (continuación)

\begin{tabular}{lll}
\hline \multicolumn{1}{c}{ Variable original } & Variable recodificada & \multicolumn{1}{c}{ Justificación } \\
\hline $\begin{array}{l}\text { Nivel de instrucción (educación) } \\
1=\text { Primaria } \\
2=\text { Secundaria } \\
3=\text { Superior } \\
4=\text { Postgrado }\end{array}$ & $\begin{array}{l}0=\text { Primaria } \\
1=\text { Otros }\end{array}$ & $\begin{array}{l}\text { Se clasificó en dos grupos tomando en con- } \\
\text { sideración el grupo mayoritario presente en } \\
\text { los pacientes con coinfección del estudio. }\end{array}$ \\
\hline $\begin{array}{l}\text { Linfocitos TCD4+ } \\
\text { Se ingresó el valor determinado por } \\
\text { el laboratorio }\end{array}$ & $0=$ Menor de 200 células/mm3 \\
\hline $\begin{array}{l}\text { Carga viral } \\
\text { Se ingresó el valor determinado } \\
\text { por el laboratorio }\end{array}$ & $\begin{array}{l}\text { Se clasificó en dos grupos tomando en con- } \\
\text { sideración el corte de } 200 \text { linfocitos TCD4+ } 200 \text { células } / \mathrm{mm} 3\end{array}$ & como indicador de inmunodepresión ${ }^{1}$ \\
\hline
\end{tabular}

Fuente: Estudio "Caracterización clínica-epidemiológica de pacientes con coinfección Criptococosis - VIH del Hospital José Rodríguez 2015 - 2016"

Elaboración: Bravo, S.

\subsection{Análisis estadístico}

El análisis estadístico se realizó sobre la base de datos llamada "VIHREC". Los programas utilizados para la elaboración de este trabajo fueron: Epidata V 3.1 para la encuesta digitalizada y elaboración de la base de datos. Los programas estadísticos para el análisis de los datos fueron el SPSS V.20.; los intervalos de confianza se calcularon en Gretl® v 1.7.1. El programa Microsoft Excel 2010 fue utilizado para la exportación de la base de datos para su respectivo análisis; el programa empleado para la digitación del trabajo de tesis fue Microsoft Word 2010 y el gestor bibliográfico, Zotero complemento de Mozilla Firefox.

El análisis univariado se efectuó a través de los estimadores puntuales y sus intervalos de confianza. El análisis de las asociaciones entre variables categóricas, se realizó mediante el contraste de independencia a través de la razón de verosimilitudes, cálculo de Razón de Prevalencias (RP), Razón de Ventajas (OR), e Intervalos de Confianza del $95 \%$ a partir de la distribución binomial. Se recategorizaron las variables: edad, nivel de instrucción, estado civil, CD4, y carga viral.

La interacción de las variables se efectuó mediante regresión logística bivariada (modelo log lineal). Para el análisis se consideró como variable respuesta coinfección criptococosis y VIH y se calculó la probabilidad de riesgo. La construcción del modelo se realizó en un solo bloque, los resultados cuentan con OR crudas y ajustadas, Intervalos de confianza del $95 \%$ y grados de libertad.

La propuesta de estudio mantuvo los preceptos de la Declaración de Helsinki de la Asociación Médica Mundial con el fin de resguardar las consideraciones éticas que se exigen en los estudios con humanos. Para garantizar la confidencialidad de los participantes se les asignó un código.

Toda la información generada fue confidencial y utilizada estrictamente para cumplir con los objetivos planteados en el estudio. No se realizaron procedimientos de coacción ni coerción.

\section{Resultados}

De los 195 pacientes VIH positivos con diagnóstico presuntivo de criptococosis se identificaron 91 (46,7\%; $\mathrm{IC}_{95 \%}$ 39,48-53,84) pacientes, que se confirmó mediante examen microscópico directo del líquido cefalorraquídeo con tinta al $100 \%$, con un tiempo de hospitalización de 14 días, de los cuales se detallarán sus características.

\subsection{Características de coinfección Criptococosis - VIH estratificado por edad, sexo}

De 56 mujeres, 29 (51,8\%; IC $_{95 \%}$ 67,8-100) tuvieron coinfección, sin embargo, el ser mujer no tiene significancia en tener coinfección con VIH, $16 \%$ (RP 1,16 IC $95 \%$ 0,851,57). Para efectos del estudio la edad de los pacientes con coinfección se recategorizó en dos grupos etarios luego de obtener la media, menores e iguales o mayores de 32 años, $56\left(58,9 \%\right.$ IC $_{95 \%}$ 46,31-66,31) participantes tenían entre 18 y 32 años, la probabilidad de que estos pacientes tengan coinfección fue de $58 \%$ (RP 1,68; $\mathrm{IC}_{95} \%$ 1,22-2,30) mayor que la probabilidad de aquellas personas mayores de 32 años, cuadro 2.

Tabla 2. Características de los pacientes con coinfección criptococosis y VIH estratificado por sexo y edad

\begin{tabular}{llllllll}
\hline Variable & Categoría & $\mathrm{N}$ & $\%^{a}$ & Total & $\mathrm{RP}$ & $\mathrm{IC}_{95 \%}$ & Valor $\mathrm{p}$ \\
\hline Sexo & & & & & 1.16 & $0,85-1.57$ & \\
& Hombre & 62 & 44,6 & 139 & & & \\
& Mujer & 29 & 51,8 & 56 & & & \\
& & 29 & & & & \\
\hline
\end{tabular}


Tabla 2. Características de los pacientes con coinfección criptococosis y VIH estratificado por sexo y edad... (continuación)

\begin{tabular}{|c|c|c|c|c|c|c|c|}
\hline Variable & Categoría & $\mathrm{N}$ & $\%^{a}$ & Total & $\mathrm{RP}$ & $\mathrm{IC}_{95 \%}$ & Valor $\mathrm{p}$ \\
\hline \multirow[t]{3}{*}{ Edad } & & & & & 1,68 & $1,22-2,30$ & $<0,01$ \\
\hline & Igual o menor de 32 años & 56 & 58,9 & 95 & & & \\
\hline & Mayor de 32 años & 35 & 35 & 100 & & & \\
\hline \multicolumn{8}{|c|}{$\begin{array}{l}a_{\text {El denominador para el porcentaje corresponde a la variable de la fila }} \\
\text { RP Razón de Prevalencia } \\
\text { IC }_{95 \%} \text { Intervalo de Confianza del } 95 \%\end{array}$} \\
\hline
\end{tabular}

3.2 Características de coinfección Criptococosis-VIH estratificado por estado civil, nivel de instrucción, uso de drogas

De 87 pacientes, $47\left(56 \%\right.$; $\mathrm{IC}_{95 \%} \%$ 46,15-71,42) estuvieron casados o unidos, encontrando que la probabilidad de que estos pacientes tengan coinfección sea de $41 \%$ (RP 1,41; $\mathrm{IC}_{95 \%}$ 1,04-1,90) mayor que la probabilidad de aquellos pacientes con otro estado civil, como se muestra en el cuadro 3 .
En cuanto al nivel de instrucción se encontró que 43 pacientes $\left(64,2 \%\right.$; $\left.\mathrm{IC}_{95 \%} 73,13-100\right)$ tuvieron mayor grado de escolaridad en un total de 67 , el tener este nivel de instrucción demostró que la probabilidad fue de $72 \%$ (RP 1,72; $\mathrm{IC}_{95 \%}$ 1,29-2,32) mayor que la probabilidad de aquellos pacientes que han cursado solo la primaria.

De un total de 82 pacientes, 45 (54,9\%; $\mathrm{IC}_{95 \%}$ 50-71,9) consumían drogas, estos pacientes tienen 1,3 veces más probabilidad de tener coinfección ( $\mathrm{RP} 1,34 \mathrm{IC}_{95} \% 1,00$ $1,81)$ que aquellos pacientes que no consumen drogas.

Tabla 3. Características de los pacientes con coinfección criptococosis y VIH estratificado por estado civil, nivel de instrucción (educación), y uso de drogas

\begin{tabular}{|c|c|c|c|c|c|c|c|}
\hline Variable & Categoría & $\mathrm{N}$ & $\%^{a}$ & Total & $\mathrm{RP}$ & $\mathrm{IC}_{95 \%}$ & Valor $\mathrm{p}$ \\
\hline \multirow[t]{2}{*}{ Estado civil } & & & & & 1,41 & $1,04-1,90$ & $<0,01$ \\
\hline & Casado o UL & 47 & 56 & 84 & & & \\
\hline \multirow[t]{2}{*}{$\begin{array}{l}\text { Nivel de instruc- } \\
\text { ción }\end{array}$} & & & & & 1,41 & $1,04-1,90$ & $<0,01$ \\
\hline & Primaria & 48 & 37.5 & 128 & & & \\
\hline \multirow[t]{3}{*}{ Drogas } & & & & & 1,34 & $1,00-1,81$ & $<0,01$ \\
\hline & $\mathrm{Si}$ & 45 & 54.9 & 82 & & & \\
\hline & No & 46 & 40.7 & 113 & & & \\
\hline
\end{tabular}

${ }^{a}$ El denominador para el porcentaje corresponde a la variable de la fila

RP Razón de Prevalencia

$\mathrm{IC}_{95} \%$ Intervalo de Confianza del $95 \%$

Fuente: Estudio "Caracterización clínica-epidemiológica de pacientes con coinfección Criptococosis - VIH del Hospital José Rodríguez 2015 - 2016"

Elaboración: Bravo, S.

\subsection{Características de coinfección Criptococosis - VIH} estratificado por Linfocitos TCD4+ y carga viral

En cuanto al conteo de linfocitos TCD4+, en el cuadro 4 se muestra que 31 pacientes presentaron un conteo mayor a $200 \mathrm{cel} / \mathrm{mm}^{3}$ (76\%; $\left.\mathrm{IC}_{95 \%} \%, 56-1,02\right)$, mientras que 59 de los coinfectados $\left(60,2 \%\right.$; $\left.\mathrm{IC}_{95 \%} 46,93-65,30\right)$ presentaron una carga viral mayor a 100.000 copias de RNA/mL, demostrando una probabilidad de coinfección de $85 \%$ (RP 1,$85 ; \mathrm{IC}_{95 \%} 2,56-1,33$ ) mayor que la de aquellos pacientes con una carga viral menor a 100.000 copias de RNA/mL.

Tabla 4. Características de los pacientes con coinfección criptococosis y VIH estratificado por estado CD4 y carga viral

\begin{tabular}{|c|c|c|c|c|c|c|c|}
\hline Variable & Categoría & $\mathrm{N}$ & $\%^{a}$ & Total & $\mathrm{RP}$ & $\mathrm{IC}_{95 \%}$ & Valor $\mathrm{p}$ \\
\hline \multirow[t]{2}{*}{ CD4 } & & & & & 0,76 & $0,56-1,02$ & $<0,01$ \\
\hline & $<200$ células $/ \mathrm{mm}^{3}$ & 60 & 42.9 & 140 & & & \\
\hline
\end{tabular}


Tabla 4. Características de los pacientes con coinfección criptococosis y VIH estratificado por estado CD4 y carga viral... (continuación)

\begin{tabular}{llllllll}
\hline Variable & Categoría & $\mathrm{N}$ & $\%^{a}$ & Total & $\mathrm{RP}$ & $\mathrm{IC}_{95 \%}$ & Valor p \\
\hline $\mathbf{C V}$ & & & & & 1,85 & $1,33-2,56 \mathrm{q}$ & $<0,01$ \\
& $<100000$ copias de $\mathrm{RNA} / \mathrm{mL}$ & 32 & 33 & 97 & & & \\
& $>100000$ copias de $\mathrm{RNA} / \mathrm{mL}$ & 59 & 60.2 & 98 & & & \\
\hline
\end{tabular}

${ }^{a}$ El denominador para el porcentaje corresponde a la variable de la fila

RP Razón de Prevalenci

$\mathrm{IC}_{95} \%$ Intervalo de Confianza del $95 \%$

Fuente: Estudio "Caracterización clínica-epidemiológica de pacientes con coinfección Criptococosis - VIH del Hospital José Rodríguez 2015 - 2016"

Elaboración: Bravo, S.

3.4 Perfil de riesgo de pacientes con coinfección Criptococosis - VIH del hospital Dr. José Daniel Rodríguez. Maridueña entre 2015 a 2016

El modelo de regresión logística se realizó con el fin de obtener el perfil de riesgo de pacientes con coinfección Criptococosis y VIH construido con las variables sexo, edad, estado civil, nivel de instrucción, uso de drogas, CD4, y carga viral. En el cuadro 6 se muestran las OR crudas y ajustadas con sus intervalos de confianza y grados de libertad para las variables mencionadas.
El sexo no fue significativo ni en la asociación bivariada ni en el modelo logístico (ORajustada 1,$13 ; \mathrm{IC}_{95} \%$ 0,492,56). Mientras tanto la edad (ORajustada 2,24; $\mathrm{IC}_{95 \%}$ 1,09-4,57), el estado civil (ORajustada 2,56; $\mathrm{IC}_{95} \%$ 1,265,26), el nivel de instrucción (ORajustada 3,36; $\mathrm{IC}_{95 \%}$ 1,52-7,42), el consumo de drogas (ORajustada 2,63; $\mathrm{IC}_{95} \%$ 1,28-5,26), la Carga viral (ORajustada 3,74; $\mathrm{IC}_{95 \%} \%$ 1,80$7,80)$, explicaron de manera significativa la variabilidad en la probabilidad de tener coinfección Criptococosis y VIH.

En cuanto al conteo de Linfocitos TCD4+ esta variable no demostró ser significativa en ningún análisis (ORajustada 2,$30 ; \mathrm{IC}_{95 \%}$ 0,99-5,34).

Tabla 5. OR crudas y ajustadas de la variable "Coinfección criptococosis y VIH" con las variables de estudio

\begin{tabular}{|c|c|c|c|c|c|c|c|c|}
\hline Variable & $\mathrm{N}$ & $\%^{b}$ & $\mathrm{OR}_{\text {cruda }}$ & $\mathrm{IC}_{95 \%}$ & gl & $\mathrm{OR}_{\text {ajustada }}{ }^{a}$ & $\mathrm{IC}_{95 \%}$ & gl \\
\hline Sexo & & & 1,33 & $0,71-2,50$ & 1 & 1,13 & $0,49-2,56$ & 1 \\
\hline Hombre & 62 & 44,6 & & & & & & \\
\hline Mujer & 29 & 51,8 & & & & & & \\
\hline Edad & & & 2,66 & $1,49-4,76$ & 1 & 2,24 & $1,09-4,57$ & 1 \\
\hline Menor o igual de 32 años & 56 & 58,9 & & & & & & \\
\hline Mayor de 32 años & 35 & 35 & & & & & & \\
\hline Nivel de instrucción & & & 3,03 & $1,63-5,55$ & 1 & 3,36 & $1,52-7,42$ & 1 \\
\hline Primaria & 48 & 37,5 & & & & & & \\
\hline Otros & 43 & 64,2 & & & & & & \\
\hline Uso de drogas & & & 1,77 & $0,99-3,14$ & 1 & 2,63 & $1,28-5,26$ & 1 \\
\hline $\mathrm{Si}$ & 45 & 54,9 & & & & & & \\
\hline No & 46 & 40,7 & & & & & & \\
\hline CD4 & & & 1,72 & $0,92-3,33$ & 1 & 2,30 & $0,99-5,34$ & 1 \\
\hline$<200$ células $/ \mathrm{mm}^{3}$ & 60 & 42,9 & & & & & & \\
\hline >200 células $/ \mathrm{mm}^{3}$ & 31 & 56,4 & & & & & & \\
\hline Carga Viral & & & 3,12 & $1,72-5,55$ & 1 & 3,74 & $1,80-7,80$ & 1 \\
\hline$<100000$ copias de RNA/mL & 32 & 33 & & & & & & \\
\hline$>100000$ copias de $\mathrm{RNA} / \mathrm{mL}$ & 59 & 60,2 & & & & & & \\
\hline
\end{tabular}

${ }^{a}$ Categoría de referencia: ser hombre, mayor de 32 años, tener otro estado civil, haber cursado la primaria, no uso de drogas, linfocitos TCD4+<200 células/mm3, Carga Viral $<100000$ copias de RNA/mL $b$ El denominador para el porcentaje corresponde a la variable de la fila

OR Razón de ventajas

$\mathrm{IC}_{95 \%}$ Intervalo de Confianza del $95 \%$

gl Grados de libertad

Fuente: Estudio "Caracterización clínica-epidemiológica de pacientes con coinfección Criptococosis - VIH del Hospital José Rodríguez 2015 - 2016"

Elaboración: Bravo, S 


\section{Discusión}

El diagnóstico precoz del VIH y el tratamiento oportuno del mismo en la actualidad constituye una de las herramientas más importantes en el ámbito de la salud. Al realizar la detección temprana de casos en la comunidad, se estaría cumpliendo con el principal objetivo de la estrategia del "Tratamiento de la infección por VIH en adultos y adolescentes" que es reducir la morbilidad y mortalidad de las personas afectadas, mejorar su calidad de vida y reducir el riesgo de transmisión del VIH recomendada por la OMS, que intenta la detección y reducción de la prevalencia y mortalidad del VIH, para de esta manera eliminar el VIH y poner fin a la epidemia de SIDA como amenaza para la salud pública para el año 2030. ${ }^{7,8}$

La criptococosis no es considerada una "enfermedad de declaración obligatoria” en ningún país del mundo, por este motivo existe poca información acerca de su incidencia en varios países de Latinoamérica como Colombia, Argentina, Perú e incluso Ecuador. Sin embargo, en un estudio retrospectivo realizado en el Hospital Paroissien de Argentina, donde se analizó el historial de 106 pacientes, se encontró una incidencia de $8,5 \%$ en la población hospitalaria estudiada. ${ }^{9}$

La prevalencia de la Criptococosis en pacientes con VIH ha aumentado en el Ecuador, en este estudio la prevalencia fue de $46,7 \%$, mientras que en estudios realizados en el mismo Hospital José Rodríguez Maridueña en años anteriores esta oscilaba entre 30 y $33 \%$. ${ }^{1,10}$

Varios estudios demostraron un cambio drástico en cuanto al predominio de la coinfección de criptococosis y VHI, Alrededor de los años 80 predominaba el sexo masculino con una relación $3: 1,{ }^{11}$ a mediados de los años 90 a pesar de que el sexo masculino predomina disminuyó a una relación de 2:1; durante los últimos años hay un crecimiento relativo de casos de SIDA en mujeres en relación a los casos en hombres, incluyendo todos los mecanismos de transmisión. ${ }^{9,12,13}$

La razón hombre: mujer muestra una tendencia a la disminución, la brecha entre ambos sexos se acorta indicando un incremento mayor en los casos de VIH-SIDA en mujeres, ${ }^{11,14}$ a pesar de estos datos, en este estudio la mayor proporción se encontró en los hombres (68\%).

La edad más frecuente de los pacientes con coinfección encontrada en este estudio fue en menores de 32 años, resultados similares a los proporcionados en trabajos realizados por varios autores como Mónaco, Bava y Kaplan tanto en Buenos Aires - Argentina como Estados Unidos respectivamente ${ }^{9,11,15}$

Ningún estudio hasta el momento se ha asociado al nivel de instrucción (educación) y estado civil. Sin embargo, en la mayoría de los estudios se ha demostrado que los pacientes con VIH estudiaron por lo menos los seis primeros años, ${ }^{16}$ y la mayoría son solteros. En este estudio se determinó que de los pacientes con mayor grado de escolaridad, casados o en unión libre son más propensos a presentar coinfección.
El uso de las drogas no solo se asocia a un aumento en los pacientes con VIH, sino también en aquellos que presentan coinfección como se demuestra en el estudio realizado en el Hospital Paroissien. ${ }^{9}$

La investigación demostró que existe una asociación entre el conteo de linfocitos TCD4+, carga viral y coinfección, constituyéndose en uno de los factores más importantes en la adquisición, propagación, persistencia y recaídas del $\mathrm{VIH}$, como demuestran varios estudios realizados en diversas poblaciones de diferentes países $;{ }^{12,14}$ lo cual coloca a la carga viral como factor predominante, mientras menor conteo de linfocitos TCD4+ y mayor carga viral los pacientes con VIH son más propensos a ser coinfectados con enfermedades oportunistas entre ellas la criptococosis. ${ }^{16-20}$

\section{Conclusiones}

La proporción de pacientes con coinfección criptococosis-VIH aumentó en el Ecuador en los últimos cinco años pese a las estrategias implementadas por el sistema de salud y al tratamiento antirretroviral gratuito otorgado por el Ministerio de Salud Pública. La situación quizás se deba a que muchos de los pacientes con VIH no cumplen a cabalidad con el tratamiento establecido, lo que genera a corto o largo plazo enfermedades oportunistas como es la Criptococosis.

Uno de los factores que influyen en la coinfección Criptococsis-VIH que se evidenció en el presente estudio fue el consumo de drogas, factor en el cual se trabaja a nivel del sector público, pero que cada año aumenta de forma significativa sobre todo en el Guayas, lo que dificulta una adecuada adherencia para el tratamiento de los pacientes, y con ello un inadecuado control de la carga viral y conteo de linfocitos TCD4+.

En base al análisis, el perfil del paciente con coinfección criptococosis y VIH sería adultos jóvenes, casado o en unión libre, con un nivel de instrucción superior a la primaria, que consume drogas, con una carga viral mayor a 100.000 copias de $\mathrm{RNA} / \mathrm{mL}$.

El hecho de que la mayoría de los pacientes estén con parejas, acarrea una mayor diseminación del VIH y con ello las implicaciones de la enfermedad. Dentro de las estrategias de atención primaria del sistema de salud se debe recomendar a todos los usuarios realizarse una prueba rápida, sin embargo, solo se realiza en casos de factores de riesgo o si existe la posibilidad de que hayan estado expuestos al VIH. Si se mejorara el primer nivel de atención se realizaría un diagnóstico temprano y la prevención en los pacientes estaría contemplada en evitar enfermedades oportunistas.

\section{Fuente de Financiamiento}

Este estudio es autofinanciado.

\section{Conflicto de Intereses}

No existen conflictos personales, profesionales, financieroso de otro tipo. 


\section{Consentimiento Informado}

Los autores cuentan con la aprobación del campus Esther, de la Universidad Rey Juan Carlos de España, previa autorización del Director Técnico y del Jefe de Docencia del Hospital Dr. José Rodíguez Maridueña. También cuentan con el consentimiento informado de los pacientes para ${ }^{15}$ la investigación, la publicación del caso y sus imágenes.

\section{Referencias Bibliográficas}

1. Sanchez-Giler S, Castro D. CARACTERIZACIóN CLíNICA DE LA CRIPTOCOCOSIS CON VIH DE LA CUIDAD DE GUAYAQUIL.. vol. 68. Cuba: Rev Cubana Med Trop; 2016.

2. González n, Tobón nM. Fungal opportunistic infections in HIV/AIDS patients. Infectio. $2006 \mathrm{dec}$;10(4):279-287.

3. Castañeda E, Lizarazo J. Protocolo de estudio y manejo de los pacientes con criptococosis. Infectio. 2012 dec;16:123-125.

4. MInisterio de Salud Pública. Guía de Práctica Clínica: Prevención, diagnóstico y tratamiento de la infección por el virus de la inmunodeficiencia humana (VIH) en embarazadas, niños, adolescente y adultos. Ecuador; 2019.

5. ONUSIDA. Ecuador; 2016.

6. Navarro, Mateo MM. Uso profesional del SPSS: autoprendizaje a través de un estudio real. Univ. Autònoma de Barcelona; 2002.

7. Organización Mundial de la Salud. OMS I Estrategia mundial del sector de la salud contra el VIH, 2016-2021; 2016.

8. Ministerio de salud pública del Ecuador. Guía de atención Integral para adultos y adolescentes con infección por VIH/SIDA. Quito; 2012.

9. Mónaco LS, Tamayo Antabak N. Criptococosis en pacientes con SIDA: estudio de casos en el Hospital Paroissien en el período 1996-2007. Revista argentina de microbiología. 2008 dec;40(4):218-221.

10. Giler SS, Castro DZ, Machín GFM, Andreu CMF, IllnaitZaragozí MT. Neurocriptococosis en el contexto de la infección con el VIH en Guayaquil, Ecuador. Revista Cubana de Medicina Tropical. 2016 may;68(1).

11. Bava AJ, Negroni R, Arechavala A, Robles AM, Bianchi M. Cryptococcosis associated with AIDS in the $\mathrm{Mu}-$ ñiz Hospital of Buenos Aires. Mycopathologia. 1997 oct;140(1):13-17.

12. Comité de SIDA. Infección por virus de inmunodeficiencia humana, embarazo y deseo de reproducción.; 2004.

13. Sierra Saldivar A. Meningitis criptocóccica: Cryptococcal meningitis. Revista del Nacional. 2013 jun;5(1):34-43.

14. Meya DB, Manabe YC, Castelnuovo B, Cook BA, Elbireer AM, Kambugu A, et al. Cost-Effectiveness of Serum Cryptococcal Antigen Screening to Prevent Deaths among HIV-Infected Persons with a CD4+ Cell Count $\leq 100$ Cells $/ \mu$ L Who Start HIV Therapy in Resource-Limited Settings. Clinical Infectious Diseases. 2010 aug;51(4):448-455.

15. Kaplan JE, Benson C, Holmes KK, Brooks JT, Pau A, Masur H, et al. Guidelines for prevention and treatment of opportunistic infections in HIV-infected adults and adolescents: recommendations from CDC, the National Institutes of Health, and the HIV Medicine Association of the Infectious Diseases Society of America. MMWR Recommendations and reports: Morbidity and mortality weekly report Recommendations and reports. 2009 apr;58(RR4):1-207; quiz CE1-4.

16. Pérez C, Hernández Y, Guzmán ME, Arias F, Nweihed L, Landaeta ME, et al. Estudio clínico-epidemiológico de la criptococosis en Venezuela, años 1994-2003. Kasmera. 2009 dec;37(2):140-147.

17. Ministerio de salud pública del Ecuador. Guía de prevención y control de las transmisión Materno Infantil del VIH y Sífilis congénita, y de la atención integral de niños/as con VIH/SIDA. Quito; 2012.

18. Miró JM. Prevención de las infecciones oportunistas en pacientes adultos y adolescentes infectados por el VIH en el año 2008. Enfermedades Infecciosas y Microbiología Clínica. 2008 jun;p. 437-464.

19. Pelaez GG, Zambrano CL, Rodriguez HL, Parra CL. Factores de riesgo de la Criptococosis en pacientes con VIH en el hospital de infectología "Dr. José Daniel Rodriguez Maridueña” en el periodo 2015-2016. RECIMUNDO. 2018 mar;2(1):157-171.

20. Awotiwon AA, Johnson S, Rutherford GW, Meintjes G, Eshun-Wilson I. Primary antifungal prophylaxis for cryptococcal disease in HIV-positive people. Cochrane Database of Systematic Reviews. 2018;(8).

Recibido: 5 de enero de 2019

Aceptado: 25 de agosto de 2019 
